\title{
The development of a national water quality database to assess shifting baselines in a changing climate
}

C.B Millek ${ }^{1,2, *}$, P. Huntsman ${ }^{1}$, R. BOUwhuis ${ }^{3}$, A. ASEMANINEJAD $^{1}$, K. RUTLEDGE ${ }^{1}$, C.J. RICKWOOD ${ }^{1}$

${ }^{1}$ Natural Resources Canada, Ottawa, Canada

${ }^{2}$ ARC Research Hub for Transforming the Mining Value Chain \& Centre for Ore Deposit and Earth Sciences, University of Tasmania, Australia *[clare.miller@utas.edu.au]

${ }^{3}$ Environment and Climate Change Canada, Gatineau, Canada

Climate change is expected to affect surface water quality in Canadian watersheds. However, there is insufficient scientific knowledge to predict how these changes are likely to be manifested. The assessment of long-term trends in historical data over time and space (e.g. watershed and regional variability) may offer insights into the potential impacts of future climate change on water quality. The compilation of three to four decades of national, provincial, and territorial water quality monitoring data across Canada was initiated in 2018. Through a bootstrap approach, the ongoing study will perform multivariate analyses of the compiled data (17,465 sample locations) to answer the following questions: (1) Are there specific metals or water quality parameters that show consistent responses to climate change that could be used as 'indicators' for future projections? (2) Are there specific areas in Canada that are more sensitive to changes in climate (i.e. hot spots)? (3) Does underlying geology influence the extent and magnitude of climate-driven changes in water quality? Subsequently, a predictive model will be built on the dataset, and validated by measuring the prediction error. This project provides an opportunity to establish a national database to track and monitor water quality in a changing climate which would be of use to both research organizations and governments as well as offering potential for citizen science applications. 